\title{
Study on the Parameter Model Affecting Coal Consumption Rate in \\ Coal-Fired Boiler
}

\author{
Qingbei Qiao
}

North China Electric Power University, BeiJing, 102206, China

Keywords: Boiler, Operating parameter, Coal consumption rate

\begin{abstract}
It is of great realistic significance to optimize operating process and control energy consumption for production segment in thermal power plants. First of all, this paper proposes the analysis model of the energy consumption of the boiler operating parameters, and then according to the definition of boiler efficiency, we construct the parameter model of coal consumption rate, which reflecting the effect of the parameter changes on coal consumption rate, including exhaust temperature, ash carbon content and excess air coefficient.
\end{abstract}

\section{Introduction}

Nowadays, coal-fired power generation is one of the main power generation modes around the world. However, compared to developed country, the energy consumption of the mainstream thermal power units is higher in China. To improve the efficiency and economic level of coal fired boiler is an important way to energy saving.

Generally speaking, the working conditions of utility boiler are always changing, and the operating parameters and operating indicators are different under different working conditions. Only by grasping the variation law of the boiler operating parameters along with working conditions can we carry out further analysis on the effect of changes of operating parameters on the coal consumption rate.

There are thousands of data on online monitoring about power station operation boiler, so it is convenient to assess the safety and economy of boiler operation by monitoring the operating parameters. The factors affecting coal consumption rate includes coal quality, excess air coefficient, exhaust temperature, ash carbon content, inlet air temperature, fineness and uniformity of pulverized coal, boiler sealing performance, heating surface contamination, etc. This paper mainly focuses on some of the parameters, including exhaust temperature, ash carbon content and excess air coefficient, to construct the parameter model to explorer their effect on coal consumption rate of power supply, so that we can put forward the boiler operation parameter adjustment plan under different working conditions, and achieve the purpose of saving energy and reducing consumption in coal-fired power generation process.

\section{Energy-Loss Analysis of Boiler Parameters}

The effect of changes in operating parameters on economics of the boiler can be regarded as changes of operation parameters leading to the change of standard coal consumption rate of power supply. The standard coal consumption rate of power supply is defined as Eq. 1.

$$
b_{s}=\frac{H_{R T}}{29720 \eta_{b} \eta_{b}(1-\varepsilon)}, \mathrm{kg} /(\mathrm{kWh})
$$


In the equation:

$H_{R T}$ — heat consumption, $\mathrm{kJ} /(\mathrm{kWh})$;

$\eta_{b}$ - - boiler efficiency, \%;

$\eta_{p}$ —- pipeline efficiency, \%;

$\varepsilon-$ - power consumption rate, \%.

Conduct derivation on Eq. 1 and obtain Eq. 2.

$$
\frac{d b_{s}}{b_{s}}=\frac{d H_{R T}}{H_{R T}}-\frac{d \eta_{b}}{\eta_{b}}-\frac{d \eta_{p}}{\eta_{p}}+\frac{d \varepsilon}{1-\varepsilon}
$$

If one term changes while other terms keep unchanged, e.g. heat consumption changes and boiler efficiency, pipeline efficiency and power consumption rate keep unchanged, there will be as Eq. 3 .

$$
\frac{d b_{S}}{b_{S}}=\frac{d H_{R T}}{H_{R T}}
$$

That is to say, when $\eta_{b}, \eta_{p}$ and $\varepsilon$ keep unchanged, change rate of coal consumption is equal to that of heat consumption. Coal consumption increases with the increase of heat consumption. When boiler efficiency changes while heat consumption, pipeline efficiency and power consumption rate keep unchanged, there will be as Eq. 4.

$$
\frac{d b_{s}}{b_{s}}=-\frac{d \eta_{b}}{\eta_{b}}
$$

When $H_{R T}, \eta_{p}$ and $\varepsilon$ keep unchanged, change rate of coal consumption is equal to negative change rate of heat consumption. The coal consumption decreases with the increase of the boiler efficiency.

The effect of parameter variation on the coal consumption rate of power supply is as Eq. 5.

$$
\Delta b_{s}=b_{s} \frac{d H_{R T}}{H_{R T}}-b_{s} \frac{d \eta_{b}}{\eta_{b}}-b_{s} \frac{d \eta_{p}}{\eta_{p}}+b_{s} \frac{d \varepsilon}{1-\varepsilon}
$$

Therefore, to calculate the effect of change in a parameter on the power supply coal consumption rate, we should calculate the effect of this parameter's change on heat consumption, boiler efficiency, pipeline efficiency and power consumption rate first of all, and then put it into the Eq. 5 to obtain the effect on power supply coal consumption rate.

In the actual operation of power plants, heat consumption, boiler efficiency and power consumption rate are constantly changing, while pipeline efficiency can be considered immutable. It will produce influence on boiler efficiency once the boiler operating parameters change, but its effect on heat consumption is negligible. So when we analyze the influence of boiler operation parameters on the coal consumption rate of power supply, we can assume that the heat consumption and pipeline efficiency are constant, and then the effect of boiler operation parameters on the coal consumption rate of power supply can be expressed as Eq. 6.

$$
\Delta b_{s}=-b_{s} \frac{d \eta_{b}}{\eta_{b}}+b_{s} \frac{d \varepsilon}{1-\varepsilon}
$$




\section{Parameter Model of Coal Consumption Rate}

Exhaust temperature. The hear loss related to exhaust temperature is defined as q2 as Eq. 7.

$$
\begin{gathered}
q_{2}=\frac{Q_{2}}{Q_{r}}=\frac{Q_{2}^{g y}+Q_{2}^{H_{2} O}}{Q_{r}}=\frac{V_{g y} \cdot c_{p t} \cdot\left(\theta_{p y}-t_{0}\right)}{Q_{r}}-\frac{V_{H_{2} O} \cdot c_{H_{2} O} \cdot\left(\theta_{p y}-t_{0}\right)}{Q_{r}} \\
V_{g y}=\left(V_{g y}^{0}\right)^{c}+(\alpha+1) \cdot\left(V_{g k}^{0}\right)^{c} \\
V_{H_{2} O}=1.24\left[\frac{9 H^{y}+W^{y}}{100}+1.293 \cdot \alpha \cdot\left(V_{g k}^{o}\right)^{c} \cdot d\right]
\end{gathered}
$$

In the equation:

$\mathrm{Q}_{2}$ - —exhaust heat loss for per kilogram of fuel, $\mathrm{kJ} / \mathrm{kg}$;

$\mathrm{Q}_{2}{ }^{g y}$ —— heat loss by dry flue gas, $\mathrm{kJ} / \mathrm{kg}$;

$\mathrm{Q}_{2}{ }^{\mathrm{H} 2 \mathrm{O}}$ ——

$V_{g y}$ - dry exhaust gas produced by per kilogram of fuel, $\mathrm{m}^{3} / \mathrm{kg}$;

$V_{\mathrm{H} 2 \mathrm{O}}$ - the volume of water vapor in the flue gas, $\mathrm{m}^{3} / \mathrm{m}^{3}$;

$c_{p y}$ — average specific heat of dry exhaust gas, $\mathrm{kJ} /\left(\mathrm{m}^{3} \cdot \mathrm{K}\right)$;

$\mathrm{C}_{\mathrm{H} 2 \mathrm{O}}$ - - average specific heat of water vapor, $\mathrm{kJ} /\left(\mathrm{m}^{3} \cdot \mathrm{K}\right)$;

$\theta_{p y}$ - exhaust temperature, ${ }^{\circ} \mathrm{C}$;

$t_{0}$ - - reference temperature, ${ }^{\circ} \mathrm{C}$;

$\left(V_{g k}{ }^{0}\right)^{c}$ - - theoretical dry air volume;

$\left(V_{g y}{ }^{0}\right)^{c}$ - — theoretical dry exhaust gas volume.

When the exhaust temperature changes, It causes a change in the boiler efficiency as Eq. 8.

$$
\Delta \eta=-K \Delta \theta_{p y}, \quad K=\frac{V_{g y} \cdot c_{p y}+V_{H_{2} O} \cdot c_{H_{2} O}}{Q_{r}}, \Delta \theta_{p y}=\theta_{p y}^{\prime}-\theta_{p y}
$$

Put Eq. 8 into Eq. 6, we can obtain the effect of change of exhaust temperature on coal consumption rate of power supply as Eq. 9.

$$
\Delta b_{s}=\frac{b_{s}}{\eta_{b}} \cdot K \cdot \Delta \theta
$$

By monitoring the $300 \mathrm{MW}$ boilers, under the conditions of constant coal quality and other operating conditions, calculate the effect of exhaust temperature on coal consumption rate of power supply at different loads as Table. 1 .

Table 1 Effect of exhaust temperature on coal consumption rate

\begin{tabular}{ccccc}
\hline Load, MW & $\mathbf{2 1 0}$ & $\mathbf{2 4 0}$ & $\mathbf{2 7 0}$ & $\mathbf{3 0 0}$ \\
\hline$\Delta \theta,{ }^{\circ} \mathrm{C}$ & 20 & 20 & 20 & 20 \\
$\Delta \eta, \%$ & -0.891 & -0.917 & -0.919 & -0.903 \\
$\Delta \mathrm{b}_{\mathrm{s}}, \mathrm{g} /(\mathrm{kWh})$ & +4.9 & +5.08 & +5.1 & +4.8 \\
\hline
\end{tabular}

We can see from the table that, along with the increase of load and exhaust temperature, coal consumption rate first increases and then decreases. 
Ash carbon content. Ash carbon content refers to the mass fraction of residual fuel after pulverized coal combustion. Ash carbon content represents the extent of coal-fired furnace in the unburnt.

The hear loss related to ash carbon content is defined as $q_{3}$ as Eq. 10.

$$
q_{3}=\frac{337.27 \cdot A^{y} \cdot \bar{C}}{Q_{r}}, \bar{C}=\frac{\alpha_{1 z} C_{1 z}}{100-C_{1 z}}+\frac{\alpha_{f h} C_{f h}}{100-C_{f h}}, \quad \alpha_{l z}+\alpha_{f h}=100 \%
$$

In the equation, $\alpha_{\mathrm{lz}}$ and $\alpha_{\mathrm{fh}}$ are respectively the carbon content of slag and fly ash. We can obtain the effect of change of ash carbon content on coal consumption rate of power supply as Eq. 11

$$
\Delta b_{s}=337.27 \frac{b_{s}}{\eta_{b}} \cdot \frac{\Delta \bar{C}}{Q_{r}}
$$

By monitoring the $300 \mathrm{MW}$ boilers, under the conditions of constant coal quality and other operating conditions, calculate the effect of ash carbon content on coal consumption rate of power supply at different loads as Table. 2 .

Table 2 Effect of ash carbon content on coal consumption rate

\begin{tabular}{ccccc}
\hline Load, MW & $\mathbf{2 1 0}$ & $\mathbf{2 4 0}$ & $\mathbf{2 7 0}$ & $\mathbf{3 0 0}$ \\
\hline$\Delta \bar{C}, \%$ & 2 & 2 & 2 & 2 \\
$\Delta \eta, \%$ & -0.504 & -0.504 & -0.504 & -0.504 \\
$\Delta \mathrm{b}_{\mathrm{s}}, \mathrm{g} /(\mathrm{kWh})$ & +2.772 & +2.792 & +2.797 & +2.679 \\
\hline
\end{tabular}

We can see from the table that, along with the increase of load and ash carbon content, its effect on coal consumption rate is gradually weakened, compared to the exhaust temperature.

Excess air coefficient. The excess air coefficient has strong coupling nature to other parameters, which is generally monitored by average oxygen content in the outlet of the province coal. Change of excess air coefficient will lead to changes in boiler efficiency, and meanwhile change of total air volume will lead to change in fan power consumption, as Eq. 12.

$$
b=f\left(\eta_{b}, \varepsilon\right)
$$

Meanwhile, boiler efficiency can be regarded as a function of excess air coefficient, exhaust temperature and ash carbon content, as Eq. 13.

$$
\eta_{b}=f\left(\alpha, \theta_{p y}, \bar{C}\right)
$$

Then, according to the boiler operation rules of power station, we can reckon the effect of excess air coefficient on coal consumption rate as Eq. 14.

$$
\frac{\partial \eta_{b}}{\partial \alpha}=\frac{\left(V_{g k}^{0}\right)^{c}}{Q_{r}} \cdot\left(\theta-t_{0}\right) \cdot\left(c_{p \cdot g y}+1.603 \cdot d_{k} \cdot c_{p \cdot H 2 O}\right)
$$

In the equation, $c_{p} \cdot g y$ is average specific heat of dry flue gas; $c_{p} \cdot H 2 O$ is average specific heat of water vapor; $\mathrm{d}_{\mathrm{k}}$ is absolute humidity of the air.

By monitoring the $300 \mathrm{MW}$ boilers, under the conditions of constant coal quality and other operating conditions, calculate the effect of excess air coefficient on coal consumption rate of power supply at different loads as Table. 3 . 
Table 3 Effect of excess air coefficient on coal consumption rate

\begin{tabular}{ccccc}
\hline Load, MW & $\mathbf{2 1 0}$ & $\mathbf{2 4 0}$ & $\mathbf{2 7 0}$ & $\mathbf{3 0 0}$ \\
\hline$\varepsilon, \%$ & 0.00076 & 0.00034 & 0.00037 & 0.0003 \\
$\Delta \eta, \%$ & -0.279 & -0.203 & -0.274 & -0.321 \\
$\Delta \mathrm{b}_{\mathrm{s}}, \mathrm{g} /(\mathrm{kWh})$ & +5.687 & +3.016 & +2.376 & +2.376 \\
\hline
\end{tabular}

\section{Conclusions}

This paper establishes a parameter model on coal consumption rate of power supply, and explores the influence degree by the changes of some parameters on specific coal consumption rate under different loads, including exhaust temperature, ash carbon content and excess air coefficient, based on simulation experimental data of the 300MW boiler.

\section{References}

[1] Smrekar J, Assadi M, Fast M, et al. Development of artificial neural network model for a coal-fired boiler using real plant data[J]. Energy, 2009, 34(2):144-152.

[2] Wang Q C, Luo Y H. The black smoke control in a chain-grate stoker-fired boiler at the time of ignition and restart of the combustion[J]. International Journal of Energy Research, 2006, 30(15):1363-1376.

[3] Xu L H, Namkung H, Kwon H B, et al. Determination of fouling characteristics of various coals under gasification condition[J]. Journal of Industrial \& Engineering Chemistry, 2009, 15(1):98-102.

[4] Ma Z, Iman F, Lu P, et al. A comprehensive slagging and fouling prediction tool for coal-fired boilers and its validation/application[J]. Fuel Processing Technology, 2007, 88(11-12):1035-1043.

[5] Zhang T F. Measures to improve the recycling effeciency of boiler heat[J]. Heilongjiang Science, 2014.

[6] Boiler P C. Pulverized coal-fired boiler[J]. Nature, 2014. 